\title{
Childhood abuse and eating psychopathology: the mediating role of core beliefs
}

Article

Accepted Version

Jenkins, P. E., Meyer, C. and Blissett, J. M. (2013) Childhood abuse and eating psychopathology: the mediating role of core beliefs. Journal of Aggression, Maltreatment \& Trauma, 22 (3). pp. 248-261. ISSN 1092-6771 doi:

https://doi.org/10.1080/10926771.2013.741665 Available at https://centaur.reading.ac.uk/76103/

It is advisable to refer to the publisher's version if you intend to cite from the work. See Guidance on citing.

To link to this article DOI: http://dx.doi.org/10.1080/10926771.2013.741665

Publisher: Taylor \& Francis

All outputs in CentAUR are protected by Intellectual Property Rights law, including copyright law. Copyright and IPR is retained by the creators or other copyright holders. Terms and conditions for use of this material are defined in the End User Agreement.

www.reading.ac.uk/centaur 
Central Archive at the University of Reading

Reading's research outputs online 


\title{
Childhood Abuse and Eating Psychopathology: The Mediating Role of Core Beliefs
}

\begin{abstract}
This study aimed to investigate the mediating role of early maladaptive schemas (core beliefs) in the relationship between childhood abuse and eating psychopathology. Three self-report questionnaires assessing experiences of childhood abuse, eating psychopathology, and levels of maladaptive schemas were administered to one hundred and eighteen female university students. Emotional abuse predicted Drive for Thinness, whereas Sexual Abuse predicted symptoms of bulimia. Mistrust/abuse beliefs were found to fully mediate relationships between childhood abuse and Drive for Thinness and Bulimia. Abandonment beliefs were also shown to be partial mediators of the relationship between sexual abuse and symptoms of bulimia. In a sample of nonclinical women, beliefs pertaining to abandonment and mistrust/abuse appeared to be important in the explanation of the relationship between recollections of childhood abuse and adult eating disorder symptoms.
\end{abstract}

KEYWORDS: eating disorder; childhood abuse; core beliefs; meditational analysis

Running head: Abuse, eating, and core beliefs 
The relationship between childhood abuse and eating pathology has been widely investigated but is still poorly understood. It is clear, however, that a direct, causal relationship does not exist, with substantial heterogeneity within both the samples used and the findings obtained (Smolak \& Murnen, 2002). Research has recently been directed towards more complex models that might expatiate this link.

In current models of eating disorders (EDs), cognitions are believed to be key in maintaining much of the pathology (e.g., Fairburn, 2008; Fairburn, Cooper, \& Shafran, 2003; Faunce, 2002). Waller et al. (2000a) suggested that early maladaptive schemas (core beliefs, or CBs), schema-level cognitions about oneself and the world (Young, 1994; Young, Klosko, \& Weishaar, 2003), are central to EDs, and bulimic disorders in particular (see also Leung, Waller, $\&$ Thomas, 1999). Following such studies, models have been proposed suggesting that CBs act as a mediator between early adverse childhood experiences and eating pathology. For example, one study has demonstrated that CBs account for the effects of sexual abuse experiences on the expression of ED symptoms in a sample of women with bulimia (Waller et al., 2001).

Childhood abuse can take many forms (Higgins \& McCabe, 2001; Kent \& Waller, 1998; Mazzeo \& Espelage, 2002), and despite obvious potential overlaps between categories, four major variants are commonly identified; physical abuse, sexual abuse, emotional abuse, and neglect. Abuse has been linked to high levels of maladaptive CBs held in adulthood (Cecero, Nelson, \& Gillie, 2004) and has also been identified as a risk factor for later eating pathology (Kent, Waller \& Dagnan, 1999; Striegel-Moore, Dohm, Pike, Wilfley, \& Fairburn, 2002; Villarroel, Penelo, Portell, \& Raich, 2011; Waller, Corstorphine, \& Mountford, 2007). However, no study has yet examined the four major abuse categories and their relationship with CBs and ED symptoms. 
Young et al. (2003) propose that CBs can be grouped into five broad categories, referred to as "domains" (p. 12). Of these, Domain 1, 'Disconnection and Rejection' beliefs, are most often related to ED symptoms (e.g., Sarin \& Abela, 2003; Waller et al., 2000a). Young et al. suggest that beliefs within Domain 1 are unconditional, and leave individuals unable to form secure attachment relationships. People with high levels of such schemas often report traumatic childhoods and it is thought that disconnection and rejection beliefs are present in the most psychologically disturbed clients (Young et al., 2003).

A number of reports have proposed that specific core beliefs act as mediators of the link between early negative childhood experiences and eating pathology (e.g., Hartt \& Waller, 2002; Jones, Leung, \& Harris, 2006; Meyer \& Gillings, 2004; Turner, Rose, \& Cooper, 2005; Waller et al., 2001). Specifically, beliefs of abandonment, defectiveness/shame, mistrust/abuse, emotional deprivation, social isolation, emotional inhibition, and subjugation, have been the most replicated as mediators of the abuse-eating link. Many of these beliefs fall under Young's Domain 1 of disconnection and rejection. Therefore, the importance of Domain 1 beliefs in predicting psychopathology seems reaffirmed. However, there is a further need to study the mediating role of core beliefs in the relationship between a broad range of childhood abuse experiences and eating disorder symptoms because no studies have yet explored how unhealthy core beliefs mediate between different kinds of abuse and ED pathology.

Furthermore, studies considering the relationship between childhood abuse and eating psychopathology have often provided conflicting results, with some confusion regarding whether different forms of abuse are more important than others in the manifestation of specific eating behaviours or cognitions (e.g. Treuer, Koperdák, Rózsa, \& Füredi, 2005). Sample sizes in this area have typically been quite small and replication with participants showing a wider range of 
disordered attitudes to eating would be helpful, in order to get a better picture of how abuse impacts on broader eating pathology rather than specific symptoms such as bulimia (e.g. Dingemans, Spinhoven, \& van Furth, 2006; Treuer et al., 2005).

Given the high prevalence of disordered eating attitudes in female university samples (e.g., Berg, Frazier, \& Sherr, 2009), the study proposed to investigate the link between early abuse, core beliefs, and current ED symptomatology. Core beliefs have been suggested as a potential mediating variable between early adverse experience and ED symptoms, but no studies have as yet looked at a full range of abusive experiences and considered associations with each of these independently.

Given the gaps in the literature at present, the aims of this study were therefore to:

(1) Explore the link between different forms of childhood abuse and disordered eating attitudes in a nonclinical group that provides a broad spectrum of responses with varying experiences of childhood abuse and eating psychopathology; and

(2) Examine the mediating role of Domain 1 core beliefs (Young et al., 2003) in the association between forms of abuse and eating psychopathology.

It is hypothesised that greater reports of abuse will be significantly associated with more unhealthy core beliefs and eating psychopathology. Furthermore, these beliefs are expected to act as significant mediators in the relationship between abuse and eating pathology.

\section{METHODS}

\section{Participants}

Participants were one hundred and eighteen female students at the University of Birmingham recruited through the Research Participation Scheme of the School of Psychology. They 
volunteered participation through poster and e-mail recruitment, and were compensated for their time through credits for psychology courses. Participants were blind to the aims of the study, but were debriefed following their participation. The study was carried out in a quiet room of the university, and participants were allowed as much time as they needed to complete the questionnaires, which were presented in a uniform order. Demographic data was collected through self-report.

The mean age of the sample was 23.2 years $(S D=3.55$; range $18-36)$ and their mean body

mass index $\left(\mathrm{BMI} ; \mathrm{kg} / \mathrm{m}^{2}\right)$ was $21.25(S D=2.62$; range 16.2-30.1). Ethical approval for the study was sought from the University of Birmingham's Ethics Committee and all participants gave informed consent.

\section{Measures}

Participants were asked to complete three measures in order to assess eating attitudes, core beliefs, and abuse history:

The Eating Disorder Inventory-2 (EDI; Garner, 1991)

The EDI is a 91-item self-report measure of ED symptoms and attitudes, which assesses eating attitudes on a six-point Likert scale, with possible responses ranging from "Always" to "Never." They include statements such as "I eat when I am upset" and "I am terrified of gaining weight." The EDI is split into a number of subscales but, as in Kent et al. (1999), only the three subscales measuring eating attitudes were used for data analysis (i.e. Drive for Thinness; Bulimia; Body Dissatisfaction). Item scores range from 0 to 3, asking respondents to rate how frequently an individual item applies, with higher scores indicating more pathological responses. The measure 
has published norms for clinical and nonclinical samples, including good reliability and validity in both eating disorder and nonclinical female samples (Garner, 1991).

Young Schema Questionnaire-Short Version (YSQ; Young, 1998)

The YSQ is a 75-item self-report questionnaire, again rated on a six-point Likert scale, where $1=$ "completely untrue of me" and 6 = "describes me perfectly." It includes items such as "For much of my life, I haven't felt that I am special to someone" and "I don't belong; I'm a loner." Higher scores represent the presence of more maladaptive schemas, or CBs, which are associated with greater risk of psychopathology. The scale is a revised version of the original, 205-item measure (Young, 1994) and the two have been found to have similar psychometric properties, and found appropriate for use, in both eating disordered and nonclinical female groups (see Waller et al., 2001). The shortened version consists of fifteen subscales (each referring to one core belief), with five items on the questionnaire contributing to each. In the current study, only those beliefs associated with Domain 1 were considered:

1. Emotional deprivation (the feeling that one's emotional needs will not be met);

2. Abandonment (the belief that close relationships will not last);

3. Mistrust/abuse (the belief that one will be mistreated by others);

4. Social isolation (the belief that one is different from others); and

5. Defectiveness/shame (the belief that one is fundamentally unlovable).

The Child Abuse and Trauma Scale (CATS; Sanders \& Becker-Lausen, 1995)

The CATS consists of 38 self-report items rated on a five-point Likert scale (range $=0-4$, where $0=$ never and $4=$ always) relating to how frequently respondents experienced abusive 
behaviours from their parents. It includes statements such as "Did you feel safe living at home?" and "Did your parents ever hit or beat you when you did not expect it?" Three distinct subscales can be calculated: Six items relating to sexual abuse (SA); a 6-item punishment scale (Physical Abuse; PA); and one assessing the degree of neglect/negative home atmosphere (Neglect). In addition, Kent and Waller (1998) have demonstrated that a further subscale, measuring childhood emotional abuse (CEA) can be extracted by using seven items from the existing CATS - six that do not form part of any other subscale, and one that is included in the Neglect subscale. The CEA subscale has been shown to have suitable validity (see Kent \& Waller, 1998) and has been used in a number of subsequent studies (e.g. Kent et al., 1999; Hartt \& Waller, 2002). Kent and Waller (1998) provide data from a large sample of nonclinical females, suggesting that the CATS is useful as a multidimensional measure of childhood abuse. Higher numbers reflect more frequent abuse but make no inference about the severity of those experiences.

\section{Data Analyses}

Preliminary analyses suggested that the data were normally distributed and so parametric tests were used throughout. Pearson's correlations were carried out, to examine the relationships between types of abuse, and the relationships between core beliefs.

To address the first aim of the study, regression analyses were conducted to look at the association between abuse and ED symptoms. Further analyses were run to determine whether CBs mediated the relationship between self-reported childhood abuse and ED symptoms. Tests of mediation were performed using the method described by Baron and Kenny (1986) who outline two stages for subsequent analysis. Firstly, the predictive power of abuse on eating symptomatology was calculated through assessment of the relationship between the independent 
(all CATS subscales) and dependent variables (EDI subscales). Secondly, regressions were performed to evaluate the relationships between core beliefs (YSQ constructs) and eating psychopathology. In a final third regression, if the independent variable (abuse) no longer has any predictive power on EDI scores once $\mathrm{CBs}$ are entered into the regression, then $\mathrm{CBs}$ are assumed to be perfect mediators of the relationship. If the relationship still remains but was weakened, core beliefs were assumed to act as partial mediators. In such cases, the Sobel test (Sobel, 1982; see also Baron \& Kenny, 1986; Preacher \& Leonardelli, 2001; Preacher \& Hayes, 2004) was used to determine whether there was a significant effect of partial mediation. If the abuse variable retained all of its predictive power, then core beliefs were assumed to have no mediating role in the relationship.

Results were analysed using SPSS version 15.0 for Windows, adopting an alpha level of 0.05 .

\section{RESULTS}

\section{Descriptive Statistics}

Participants' mean scores on the CATS, YSQ and EDI are shown in Table 1.

\section{[INSERT TABLE 1 HERE]}

Scores on the EDI and (emotional) abuse are similar to previous studies of undergraduates (e.g., Hund \& Espelage, 2006) and lower than clinical samples (e.g., Waller et al., 2000b).

[INSERT TABLE 2 HERE] 
Correlations between reported abuse and core beliefs are shown in Table 2. Reports of the different types of abuse were significantly correlated. Reports of core beliefs were also significantly positively correlated. There were also strong positive correlations between abuse histories and unhealthy core beliefs.

Core beliefs as potential mediators of the abuse/eating pathology link

Multiple regression analyses were used to determine whether CATS scores predicted EDI scores. Due to significant correlations between CATS scores, all types of abuse were entered into the regression simultaneously, to identify which was the best predictor of each EDI subscale (see Table 3).

[INSERT TABLE 3 HERE]

Emotional abuse was the only significant predictor of Drive for Thinness when all other abuse variables were also entered into the regression. Sexual abuse was the only significant predictor of symptoms of Bulimia when all other abuse variables were entered into the regression. There were no significant relationships between history of abuse or neglect and body dissatisfaction in this sample. A further set of regressions examined the relationships between core beliefs and EDI subscales. Because of the significant correlations between YSQ scores, all beliefs were entered into the regression simultaneously, to identify which was the best predictor of each EDI subscale. Mistrust/abuse, social isolation and defectiveness/shame beliefs predicted Drive for Thinness. Abandonment was the only predictor of symptoms of bulimia, when all other 
predictors were entered into the regression. The only significant predictor of Body Dissatisfaction was defectiveness/shame beliefs.

\section{[INSERT TABLE 4 HERE]}

Regressions with all types of abuse as predictors of core beliefs are illustrated in Table 4. Sexual Abuse predicted abandonment, mistrust/abuse, and social isolation beliefs. Physical Abuse predicted defectiveness/shame beliefs. Neglect predicted emotional deprivation beliefs. Emotional abuse predicted mistrust/abuse beliefs (see Table 4).

\section{Mediational Analyses}

As a result of the reported associations, there were two potential functional mediational pathways that could be tested: an examination of whether mistrust/abuse beliefs mediated the relationship between emotional abuse and Drive for Thinness; and an examination of whether abandonment beliefs mediated the relationship between Sexual Abuse and symptoms of bulimia. Two final regression analyses were run to establish whether the significant association between CATS scores and EDI scores (Drive for Thinness and Bulimia) remained when core beliefs were entered into the regression equation.

Mistrust/abuse beliefs fully mediated the relationship between Emotional Abuse and Drive for Thinness (Emotional Abuse; $p=.11$; mistrust/abuse as mediator: $\mathrm{B}=1.20, \mathrm{SEB}=.49, \beta=.259$, $p<.05)$. 
Abandonment beliefs partially mediated the relationship between: sexual abuse and bulimia (Sobel's test $=2.16, p<.05)$.

\section{DISCUSSION}

The present study was designed as an extension of previous work looking at the role of core beliefs (CBs) in the relationship between early experience and eating disorder (ED) pathology. The study looked at a number of forms of childhood abuse, and investigated the potential for CBs to act as mediators in the relationship between abuse and ED symptoms. The findings indicate that $\mathrm{CBs}$ relating to mistrust/abuse and abandonment were particularly important in the link between recollections of childhood abuse and eating attitudes in a non-clinical sample. The study also shows significant correlations between experiences of abuse and maladaptive core beliefs. Overall, the results support models implicating specific cognitive structures as important in the development of ED pathology (e.g., Leung et al., 1999; Waller et al., 2000a), although core beliefs did not predict the EDI subscale of body dissatisfaction. In this nonclinical sample, it seems unlikely that body dissatisfaction is associated with Young's core beliefs (e.g., Waller, Dickson, \& Ohanian, 2002), and body dissatisfaction may develop through mechanisms other than core beliefs (e.g., Rodgers, Paxton, \& Chabrol, 2009). Nonetheless, this study supports existing work suggesting that the cognitive interpretations of abusive experiences may be more clinically important than the precise nature of those experiences (e.g., Wright, Crawford, \& Del Castillo, 2009).

Mistrust/abuse beliefs fully mediated the relationship between childhood emotional abuse and drive for thinness beliefs. In line with existing theories (e.g., Meyer \& Gillings, 2004; Preti, 
Incani, Camboni, Petretto, \& Masala, 2006; Polivy \& Herman, 2002), it may be the case that striving for an idealized body shape (i.e., Drive for Thinness) develops as a coping mechanism to compensate for an underlying fear of being taken advantage of that often results from abusive upbringings (e.g., Cooper, Todd, \& Wells, 1998). Similarly, the link between Sexual Abuse with symptoms of bulimia is compatible with hypotheses that bulimic behaviours act as blocking mechanisms to painful thoughts and experiences (e.g., Heatherton \& Baumeister, 1990). However, while interesting suggestions for clinical work, longitudinal studies involving ED patients may be needed to confirm these theories.

Abandonment was also found to partially mediate the link between Sexual Abuse and Bulimia, partially replicating previous suggestions that abandonment beliefs are important in the link between negative upbringing and ED symptoms (Jones, Leung, \& Harris, 2006; Leung, Thomas, \& Waller, 2001). Similarly, the results provide partial support for suggestions that individual reactions are important in the relationship between sexual abuse and ED symptoms (Treuer et al., 2005).

Although the findings of the current study extend earlier work and introduce new pathways, there were some limitations. The links described with a nonclinical sample are likely to be mirrored in clinical samples but may be weaker or less frequent, and may also be subject to a source bias given the use of self-report. Other forms of coping (including other, conditional, CBs; see Young et al., 2003) and behavioural phenotypes, such as impulsivity and dissociation, were not assessed, and have been shown to mediate similar relationships (e.g., Kent et al., 1999; Tasca et al., 2009). The present study has the advantage of considering both partial and full mediation mechanisms (Baron \& Kenny, 1986), but in doing this, carries out a number of 
statistical analyses. Thus, the chances of some pathways being found to be significant when they may not be (Type I error) are relatively high, and might therefore be interpreted with caution.

The results of the present study are only suggestive of relationships, particularly given the use of a cross-sectional design, and no causal inferences can be drawn. Longitudinal studies will be required in order to look at more complex path analyses, perhaps offering further insight into how the cognitive and behavioural sequelae of abuse develop over time. Other research might also look at why certain people use eating behaviours as relief from abusive experiences rather than adopting other maladaptive behaviours or healthy coping mechanisms.

In summary, links were found between self-reported childhood abuse and eating psychopathology, with core beliefs of mistrust/abuse and abandonment found to mediate pathways between experiences of abuse, and drive for thinness and bulimia., corresponding to existing reports (e.g., Turner et al., 2005; Waller et al., 2000a; 2001). This study, alongside future work, is hoped to inform cognitive treatment of both eating disorders and reactions to traumatic abuse in childhood. 


\section{REFERENCES}

Berg, K. C., Frazier, P., \& Sherr, L. (2009). Change in eating disorder attitudes and behavior in college women: Prevalence and predictors. Eating Behaviors, 10, 137-142.

Cecero, J. J., Nelson, J. D., \& Gillie, J. M. (2004). Tools and tenets of schema therapy: Toward the construct validity of the Early Maladaptive Schema Questionnaire-Research Version (EMSQ-R). Clinical Psychology and Psychotherapy, 11, 344-357.

Cooper, M. J., Todd, G., \& Wells, A. (1998). Content, origins and consequences of dysfunctional beliefs in anorexia nervosa and bulimia nervosa. Journal of Cognitive Psychotherapy, 12, 213-230.

Dingemans, A. E., Spinhoven, Ph., \& van Furth, E. F. (2006). Maladaptive core beliefs and eating disorder symptoms. Eating Behaviors, 7, 258-265.

Fairburn, C. G. (2008). Cognitive behavior therapy and eating disorders. New York, NY: Guilford Press.

Fairburn, C. G., Cooper, Z., \& Shafran, R. (2003). Cognitive behaviour therapy for eating disorders: A "transdiagnostic" theory and treatment. Behaviour Research and Therapy, 41, 509-528.

Faunce, G. J. (2002). Eating disorders and attentional bias: A review. Eating Disorders, 10, 125-139.

Feiring, C. (2005). Emotional development, shame, and adaptation to child maltreatment. Child Maltreatment, 10, 307-310.

Hartt, J., \& Waller, G. (2002). Child abuse, dissociation, and core beliefs in bulimic disorders. Child Abuse and Neglect, 26, 923-938. 
Heatherton, T. F., \& Baumeister, R. F. (1991). Binge eating as escape from self-awareness. Psychological Bulletin, 110, 86-108.

Higgins, D. J., \& McCabe, M. P. (2001). Multiple forms of child abuse and neglect: Adult retrospective reports. Aggression and Violent Behaviour, 6, 547-578.

Hughes, M. L., Hamill, M., van Gerko, K., Lockwood, R., \& Waller, G. (2006). The relationship between different levels of cognition and behavioural symptoms in the eating disorders. Eating Behaviors, 7, 125-133.

Hund, A. R., \& Espelage, D. L. (2006). Childhood emotional abuse and disordered eating among undergraduate females: Mediating influence of alexithymia and distress. Child Abuse and Neglect, 30, 393-407.

Jones, C. J., Leung, N., \& Harris, G. (2006). Father-daughter relationship and eating psychopathology: The mediating role of core beliefs. British Journal of Clinical Psychology, 45, 319-330.

Kent, A., \& Waller, G. (1998). The impact of childhood emotional abuse: An extension of the Child Abuse and Trauma Scale. Child Abuse and Neglect, 22, 393-399.

Kent, A., Waller, G., \& Dagnan, D. (1999). A greater role of emotional than physical or sexual abuse in predicting disordered eating attitudes: The role of mediating variables. International Journal of Eating Disorders, 25, 159-167.

Leung, N., Waller, G., \& Thomas, G. (1999). Core beliefs in anorexic and bulimic women. Journal of Nervous and Mental Disease, 187, 736-741.

Leung, N., Thomas, G., \& Waller, G. (2001). The relationship between parental bonding and core beliefs in anorexic and bulimic women. British Journal of Clinical Psychology, 39, 205-213. 
Mazzeo, S. E., \& Espelage, D. L. (2002). Association between childhood physical and emotional abuse and disordered eating attitudes in female undergraduates: An investigation of the mediating role of alexithymia and depression. Journal of Consulting and Clinical Psychology, 49, 86-100.

Meyer, C., \& Gillings, K. (2004). Parental bonding and bulimic psychopathology: The mediating role of mistrust/abuse beliefs. International Journal of Eating Disorders, 35, 229-233.

Murray, C., Waller, G., \& Legg, C. (2000). Family dysfunction and bulimic psychopathology: The mediating role of shame. International Journal of Eating Disorders, 28, 84-89.

Polivy, J., \& Herman, C. P. (2002). Causes of eating disorders. Annual Review of Psychology, $53,187-213$.

Preti, A., Incani, E., Camboni, M. V., Petretto, D. R., \& Masala, C. (2006). Sexual abuse and eating disorder symptoms: The mediator role of bodily dissatisfaction. Comprehensive Psychiatry, 47, 475-481.

Rodgers, R. F., Paxton, S. J., \& Chabrol, H. (2009). Effects of parental comments on body dissatisfaction and eating disturbances in young adults: A sociocultural model. Body Image, 6, 171-177.

Sarin, S., \& Abela, J. R. Z. (2003). The relationship between core beliefs and a history of eating disorders: An examination of the life stories of university students. Journal of Cognitive Psychotherapy, 17, 359-374.

Smolak, L. \& Murnen, S. K. (2002). A meta-analytic examination of the relationship between child sexual abuse and eating disorders. International Journal of Eating Disorders, 31, 136-150. 
Striegel-Moore, R. H., Dohm, F.-A., Pike, K. M., Wilfley, D. E., \& Fairburn, C. G. (2002). Abuse, bullying, and discrimination as risk factors for binge eating disorder. American Journal of Psychiatry, 159, 1902-1907.

Tasca, G. A., Szadkowski, L., Illing, V., Trinneer, A., Grenon, R., Demidenko, N., et al. (2009). Adult attachment, depression, and eating disorder symptoms: The mediating role of affect regulation strategies. Personality and Individual Differences, 47, 662-667.

Treuer, T., Koperdák, M., Rózsa, S., \& Füredi, J. (2005). The impact of physical and sexual abuse on body image in eating disorders. European Eating Disorders Review, 13, 106-111.

Turner, H. M., Rose, K. S., \& Cooper, M. J. (2005). Parental bonding and eating disorder symptoms in adolescents: The mediating role of core beliefs. Eating Behaviors, 6, 113118.

Villarroel, A. M., Penelo, E., Portell, M., \& Raich, R. M. (2011). Childhood sexual and physical abuse in Spanish female undergraduates: Does it affect eating disturbances? European Eating Disorders Review. DOI: 10.1002/erv.1086

Waller, G. (1992). Sexual abuse and the severity of bulimic symptoms. British Journal of Psychiatry, 161, 90-99.

Waller, G., Corstorphine, E., \& Mountford, V. (2007). The role of emotional abuse in the eating disorders: Implications for treatment. Eating Disorders, 15, 317-331.

Waller, G., Ohanian, V., Meyer, C., \& Osman, S. (2000a). Cognitive content among bulimic women: The role of core beliefs. International Journal of Eating Disorders, 28, 235-241.

Waller, G., Hamilton, K., Elliott, P., Lewendon, J., Stopa, L., et al. (2000b). Somatoform dissociation, psychological dissociation, and specific forms of trauma. Journal of Trauma and Dissociation, 1, 81-98. 
Waller, G., Meyer, C., Ohanian, V., Elliott, P., Dickson, C., \& Sellings, J. (2001). The psychopathology of bulimic women who report childhood sexual abuse: The mediating role of core beliefs. Journal of Nervous and Mental Disease, 189, 700-708.

Waller, G., Dickson, C., \& Ohanian, V. (2002). Cognitive content in bulimic disorders: Core beliefs and eating attitudes. Eating Behaviors, 3, 171-178.

Wiedermen, M. W., \& Pryor, T. L. (2000). Body dissatisfaction, bulimia, and depression among women: The mediating role of drive for thinness. International Journal of Eating Disorders, 27, 90-95.

Wright, M. O., Crawford, E., \& Del Castillo, D. (2009). Childhood emotional maltreatment and later psychological distress among college students: The mediating role of maladaptive schemas. Child Abuse and Neglect, 33, 59-68.

Young, J. E. (1994). Cognitive therapy for personality disorders: A schema-focussed approach ( $2^{\text {nd }}$ Ed.). Sarasota, FL: Professional Resource Press.

Young, J. E. (1998). The Young Schema Questionnaire: Short Form. Available at http://www.schematherapy.com/id54.htm.

Young, J. E., Klosko, J. S., \& Weishaar, M. E. (2003). Schema therapy: A practitioner's guide. New York, NY: Guilford Press. 